\title{
Degradation Studies on LiFePO4 cathode
}

Scipioni, Roberto; Jørgensen, Peter Stanley; Hjelm, Johan; Norby, Poul; Rasmussen, Claus Nygaard; Jensen, Søren Højgaard

Published in:

Electrochemical Society. Meeting Abstracts (Online)

Publication date:

2014

Document Version

Publisher's PDF, also known as Version of record

Link back to DTU Orbit

Citation (APA):

Scipioni, R., Jørgensen, P. S., Hjelm, J., Norby, P., Rasmussen, C. N., \& Jensen, S. H. (2014). Degradation Studies on LiFePO 4 cathode. Electrochemical Society. Meeting Abstracts (Online), MA2014-02(5), 382.

\section{General rights}

Copyright and moral rights for the publications made accessible in the public portal are retained by the authors and/or other copyright owners and it is a condition of accessing publications that users recognise and abide by the legal requirements associated with these rights.

- Users may download and print one copy of any publication from the public portal for the purpose of private study or research.

- You may not further distribute the material or use it for any profit-making activity or commercial gain

- You may freely distribute the URL identifying the publication in the public portal

If you believe that this document breaches copyright please contact us providing details, and we will remove access to the work immediately and investigate your claim. 


\title{
Degradation Studies on $\mathrm{LiFePO}_{4}$ cathode
}

\author{
Wednesday, 8 October 2014 \\ Expo Center, 1st Floor, Center and Right Foyers (Moon Palace Resort) \\ R. Scipioni (Department of Energy Conversion and Storage, Technical University of Denmark), P. \\ S. Jørgensen (Technical University of Denmark), J. Hjelm, P. Norby (Department of Energy \\ Conversion and Storage, Technical University of Denmark), C. N. Rasmussen (Department of \\ Electrical Engineering, Technical University of Denmark), and S. H. Jensen (Department of Energy \\ Conversion and Storage, Technical University of Denmark) \\ Lithium-ion batteries are a promising technology for automotive application, but limited \\ performance and lifetime is still a big issue. The aim of this work is to study and address \\ degradation processes which affect $\mathrm{LiFePO}_{4}$ (LFP) cathodes - one of the most common cathodes in \\ commercial Li-ion batteries.
}

In order to evaluate how the LFP cathode is affected by C-rate a LFP working electrode, Lithium metal foil counter electrode and Lithium metal reference electrode was tested in a 3-electrode setup with a standard $1 \mathrm{M} \mathrm{LiPF}_{6}$ in 1:1 EC/DMC electrolyte and glass fiber separator. The working electrode/counter electrode was subjected to several charge/discharge cycles between $3.0 \mathrm{~V}$ and 4.0 $\mathrm{V}$ at different discharge rates. Figure 1 shows the voltage profile of the LFP electrode (solid line) and full battery (dotted line) during charge/discharge process. It is seen that the higher the C-rate, the higher is the polarization furnished by the counter electrode which reduces the capacity.

In Figure 2, the discharge capacity [mAh/g] is plotted vs the number of charge/discharge cycles. Series of 10 cycles at a given C-rate was applied to the battery. Each series was followed by a C/10 cycle (green points). A linear fit has been applied to the first series (omitting first two cycles where instability of the system is observed), in order to calculate the degradation rates.

High C-rates are seen to affect the discharge capacity, but the capacity is almost completely recovered (green points) and only a limited degradation occurs.

Impedance spectroscopy has been also applied to investigate the LFP cathode degradation. Figure 3 shows the imaginary part of the impedance measured at 50\% State-of-Charge after each series of cycles. The relative increase in the impedance arc around $1 \mathrm{KHz}$ (assumed to be associated with charge transfer resistance at the LFP particle surfaces) is seen to gradually decrease with increasing number of series. This indicates that more cycles per series is needed to establish a convincing relation between C-rate and degradation.

The degradation studies will be coupled with FIB/SEM analysis in order to observe changes in the pore structure or micro cracks that would affect electronic percolation. Figure 4 displays an example of a fresh LFP cathode after FIB cutting. White particles are LFP grains while the black area contains carbon particles and pores, which are difficult to distinguish from each other. Substitution of the epoxy resin with a silicon resin increases the contrast between pores and carbon particles [1] and this will be used in the forthcoming FIB/SEM analysis.

\section{References}


[1] M. Ender et al, Journal of The Electrochemical Society, 159 (7) A972-A980 (2012)

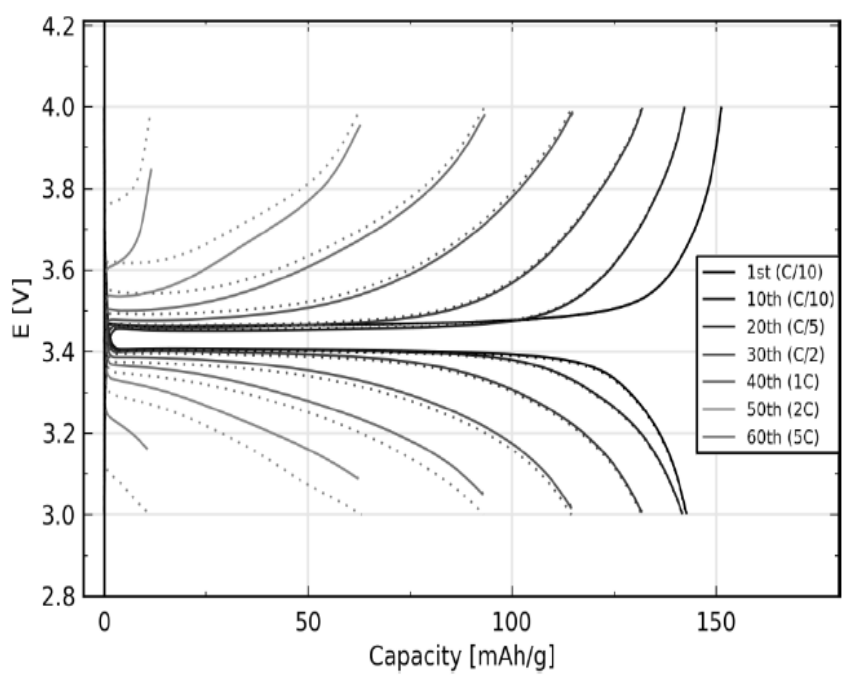

Figure 1. Charge-Discharge curves of $\mathrm{LiFePO}_{4}$ cathode (solid line) and full battery (dotted line) at different C-rate

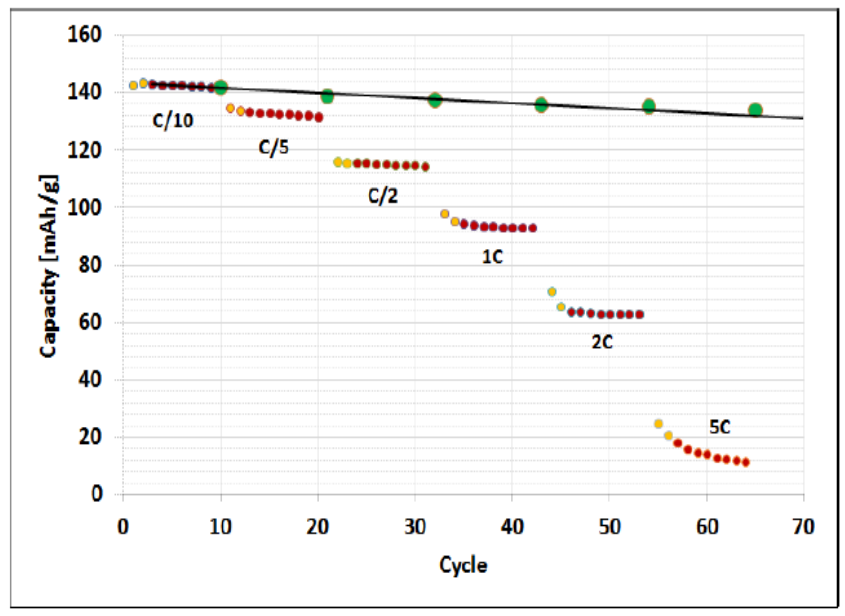

Figure 2. Capacity fading vs cycle number.

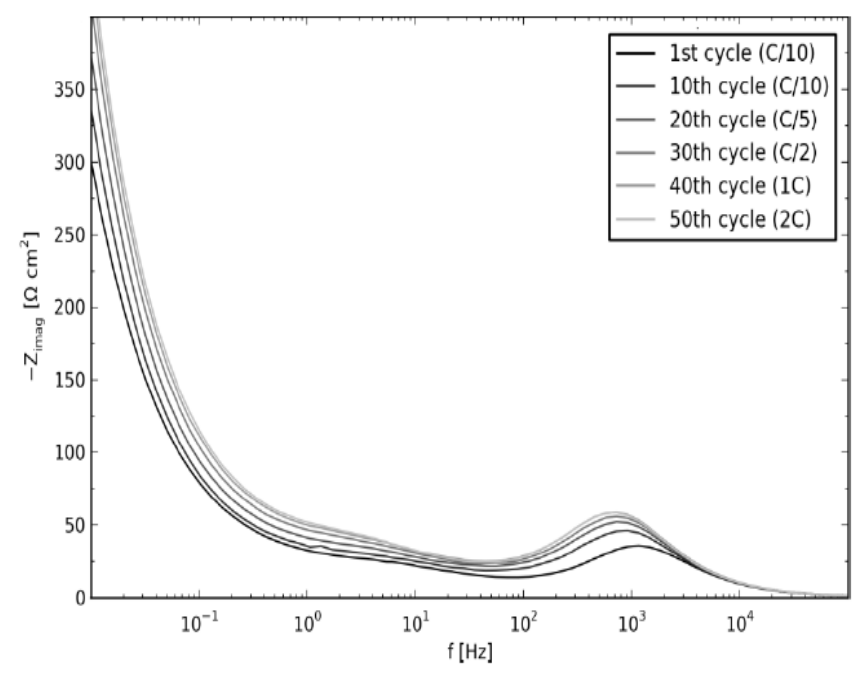

Figure 3. Bode plot of the imaginary part of the LFP impedance measured at $50 \% \mathrm{SOC}$ after each series of cycles

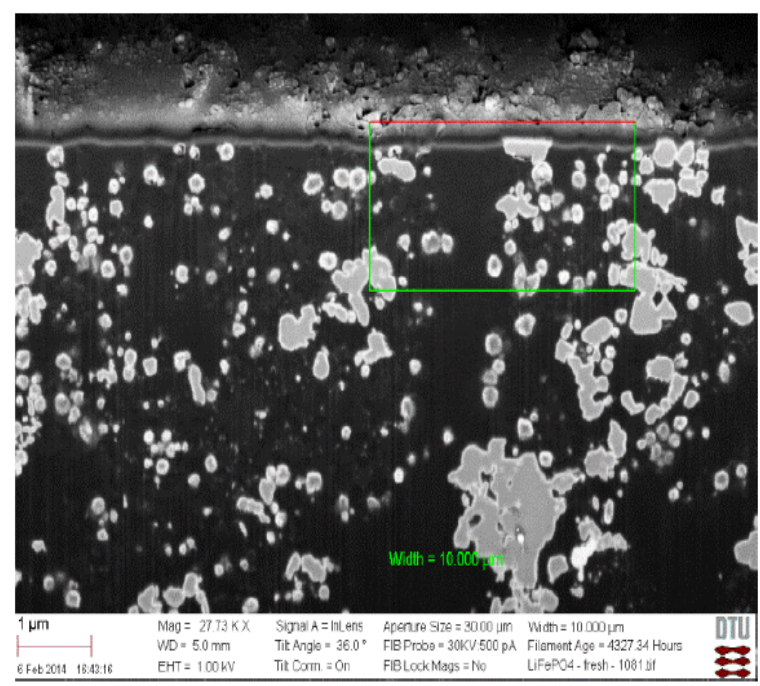

Figure 4. SEM image of the $\mathrm{LiFePO}_{4}$ electrode after FIB cutting. 